\title{
CONFLITOS E PONTES INTERGERACIONAIS NAS RESISTÊNCIAS FEMINISTAS AUTONOMISTAS TRANSLOCAIS LATINOAMERICANAS
}

\author{
Laura França Martello ${ }^{1}$
}

\begin{abstract}
Resumo: As práticas e propostas dos feminismos jovens são diversas e têm ganhado cada vez mais expressão no campo feminista. A pesquisa realizou, através de pesquisa de campo e entrevistas com participantes, um mapeamento de práticas dos feminismos jovens, enfocando encontros e festivais feministas autonomistas brasileiros e latinoamericanos que ocorreram entre 2011 e 2014. Situando essas expressões em suas continuidades e rupturas com outras atuações feministas ao longo da trajetória histórica do movimento, e retomando os debates e conflitos que ocorreram nos encontros latinoamericanos no contexto político das últimas décadas, analisamos como os feminismos jovens autonomistas buscam transformação social através da formação de culturas e comunidades de resistência que forneçam o apoio para possibilitar a vivência, no presente e no cotidiano, de relações que se pautem por princípios feministas. São características desses ativismos a criação de metodologias e pedagogias para a construção da autoconsciência e autodeterminação através do compartilhamento de experiências subjetivas, de visões interpretativas sobre a realidade e de técnicas de autodefesa e outras tecnologias micropolíticas corporais. As análises do campo se concentraram nas práticas organizativas do movimento, apresentando e refletindo criticamente, a partir das falas das colaboradoras da pesquisa, sobre as propostas de autonomia, autogestão e faça-você-mesma, a construção de espaços específicos entre mulheres, lésbicas e trans, a criação de redes de cuidada e apoia mútua, e a busca pela horizontalidade. Analisou-se também os conflitos em torno das relações de poder e as propostas de combate a opressões entre feministas, em especial o etarismo e adultocentrismo, lesbofobia. transfobia, racismo e especismo.
\end{abstract}

Palavras-chave: Feminismos. Juventude. Autonomia. Movimentos sociais. América Latina.

1 Doutoranda em Ciência Política pelo Programa de Pós Graduação em Ciência Política pela Universidade de Minas Gerais. Email: laurafrancamartello@gmail.com 


\section{AS RELAÇÕES INTERGERACIONAIS NOS FEMINISMOS AUTONOMISTAS NO CONTEXTO LATINOAMERICANO}

A presente pesquisa tem como principal objetivo analisar as dinâmicas intergeracionais nos feminismos autonomistas ${ }^{2}$ latinoamericanos, especialmente no que tange (1) às suas formas de organização e ação política, (2) suas práticas interseccionais de combate a opressões, e (3) de suas políticas de tradução de temáticas caras ao campo dos movimentos antiautoritários, anticapitalistas e antipatriarcais. A noção de feminismo autonomista aqui busca compreender a interseção entre a corrente do feminismo autônomo latinoamericano, que enfatiza a importância das transformações micropolíticas no cotidiano, e os autonomismos latinoamericanos, que têm se difundido especialmente nos movimentos de protesto antisistêmicos e altermundialistas.

Gostaríamos de sublinhar, primeiramente, que não é nosso objetivo reproduzir uma dicotomia estanque entre feministas institucionais e autônomas. Nas relações imbricadas entre os movimentos sociais e o Estado na América Latina, especialmente em países em que a esquerda teve ou tem forte presença no governo, muitas vezes as mesmas ativistas possuem atuação tanto em grupos e espaços autonomistas, quanto em organizações formais de defesas de direitos e em instâncias institucionais do Estado.

A proposta aqui consiste em trazer para o debate as expressões e atuações dos feminismos autonomistas, que têm sido menos abordadas nos estudos e análises dos movimentos sociais, em especial na Ciência Política, com o objetivo de promover maior interlocução entre os conteúdos trabalhados. Nesse sentido, além das relevantes críticas ao processo de institucionalização do

2 \#O uso do termo "autonomista" aqui foi adotado para caracterizar a autonomia como processo e como horizonte buscado pelos movimentos em questão, e não como constatação de um estado de ser que considero não ser totalmente efetivo, já que várias dinâmicas de dominação e hegemonia ainda permeiam esses espaços. É também uma alternativa ao uso do termo "feminismo autônomo" por este ter sido fortemente marcado por um grupo de feministas que, num momento histórico específico se confrontou com o chamado "feminismo institucional" no contexto dos Encontros Feministas Latino-americanos e Caribenhos, processo que será abordado ao longo do texto. Muitas das expressões que abarcamos aqui não participam, não se identificam ou mesmo desconhecem os discursos e espaços construídos por essa "corrente feminista autônoma". Se contrapõe, portanto, a construção de uma narrativa unificada sobre esse campo e afirma as diferenças de posicionamento e práticas organizativas entre feministas autonomistas. O termo "autonomismo" também faz uma conexões com as expressões anticapitalistas, anti-hieráquicas, adeptas à ação direta e focadas na transformação micropolítica dos modos de vida que esse termo designa nos movimentos sociais em diversas regiões do mundo. 
feminismo e sua inserção nas estruturas estatais (ITACARAMBY, 2012), advindas de vertentes com fortes influências comunistas e anarquistas, buscamos contemplar algumas temáticas que tiveram pouca inserção e acabaram marginalizadas no processo de diálogo entre as organizações feministas e os Estados.

$\mathrm{O}$ foco nas relações intergeracionais se deve à emergência recente das jovens feministas como sujeito político no campo do feminismo, contestando diversas lógicas hierárquicas baseadas em pertencimentos etários e em tempo e trajetória no movimento. No âmbito da participação institucional no Estado (SILVA, 2009), e no contexto dos grandes encontros feministas latinoamericanos (ALVAREZ, 2003), a questão geracional se manifesta na luta por representação das jovens feministas e na luta por reconhecimento das demandas específicas das mulheres jovens (MARTELLO, 2013).

De forma não desconectada mas diferente das que se dão nesses âmbitos, em encontros e festivais feministas autônomos os conflitos intergeracionais de poder têm se dado principalmente em torno das narrativas históricas contadas e reconhecidas nos feminismos autônomos latino-americanos. Nesse contexto, a ação das feministas jovens autonomistas diante da ainda pequena visibilidade de suas produções, debates e ações, tem sido a difusão de narrativas próprias acerca de suas atuações e propostas políticas e a construção de espaços de sociabilidade e resistência (MARTELLO, 2015).

Reconhecendo os diversos aportes e contribuições criativas nas práticas de feministas jovens autonomistas, não podemos deixar de perceber, entretanto, uma forte continuidade entre muitas das temáticas com maior fluxo no presente momento e os debates propostos por feministas de inspiração socialista libertária e anarquista desde o início do século XIX.

Um exemplo desses conteúdos é o debate sobre relações livres e nãomonogamia, que se encontra em plena efervescência em arenas de debate entre feministas jovens e muitas vezes é tomado como inédito por não figurar nas historiografias lineares do feminismo. As análises do que seria a primeira onda do feminismo muitas vezes se referem a este período como um momento de luta focado na conquista do voto e de direitos políticos básicos. Entretanto, figuras com tendências ideológicas afins ao que hoje conhecemos como anarcofeminismo, como Maria Lacerda de Moura, publicaram diversos textos e realizaram debates sobre relações livres e não monogamia nos primeiros anos do século passado (MARQUES; PEDRO, 2012). A discussão se encontra presente também em períodos associados com a segunda e a terceira onda 
feminista.

Não acreditamos que seja interessante, porém, adotar abordagens historiográficas que dividem os feminismos em vertentes, pois acabam por estabelecer uma linearidade interna às correntes feministas e gerando limites e distâncias intransponíveis que dificultam a percepção dos trânsitos entre perspectivas e práticas políticas diversas.

Para analisar essa realidade, tomaremos a proposta teórica de Sonia Alvarez (2014) de pensarmos os feminismos como "campo(s) discursivo(s) de ação" em que linguagens, sentidos e visões de mundo são parcialmente compartilhados e quase sempre disputados. Diferentemente da noção de movimentos sociais como um aglomerado de organizações voltadas para uma determinada problemática, a ideia de campos discursivos de ação sugere redes políticocomunicativas, constitutivamente perpassadas por poderes e conflitos, que se estendem para além do que foi consagrado como "sociedade civil".

As conexões entre os feminismos autonomistas de diferentes regiões da América Latina serão pensadas a partir do conceito de translocalidades (COSTA; ALVAREZ, 2009) que liga as geografias de poder em diferentes âmbitos - locais, regionais, nacionais e globais -, às diferentes posições de sujeito - pertencimentos de gênero, sexualidade, classe e étnico-raciais. Os sujeitos políticos translocais, aqui encarnados em feministas autonomistas, fundam suas políticas de localização na relação dos múltiplos marcadores sociais com os diversos modos de dominação. As perspectivas e subjetividades "translocais" estariam investidas na tradução cultural, facilitando o diálogo entre posições políticas diferentes e aparentemente incompatíveis através de um processo dinâmico de mediação através das fronteiras discursivas, políticas, teóricas, linguísticas, geográficas e de assimetrias de poder (COSTA; ALVAREZ, 2009).

Buscaremos, portanto, escapar o máximo possível ao enquadramento tradicional da política comparada fixada no recorte do Estado-Nação, com base nas amplas críticas ao enquadramento Westphaliano e sua inadequação para se pensar política numa perspectiva feminista (FRASER, 2005). A crítica decolonial nos ensina sobre o trabalho analítico localizado nas fronteiras (ANZALDUA, 1999; MOHANTY, 2005) e nos atenta para a necessidade de valorizar os Feminismos Nuestroamericanos (GARGALLO, 2006) e por isso teremos como principais referências teóricas lésbicas e negras do feminismo autônomo latino-americano (CURIEL, 2007; ESPINOSA-MIÑOSO, 2009; NASCIMENTO, 2013). 
A partir dessas fundamentações teóricas, desenvolvemos um trabalho de campo translocal, analisando como o componente geracional afeta o tráfico de teorias e práticas, influenciando conflitos e pontes nos fluxos translocais (COSTA; ALVAREZ, 2009) entre feministas autonomistas.

A pesquisa consiste em uma perspectiva localizada numa experiência subjetiva muito própria e que reflete uma posição social específica de uma pessoa que ocupa lugares subalternos como mulher, como lésbica e como latinoamericana, e que também possui marcas de privilégio como a cisgenereidade ${ }^{3}$, a branquitude e uma trajetória de classe e acadêmica privilegiadas. É um texto que traz expressões de processos também coletivos, que perpassam os mais diversos âmbitos político-teóricos nos quais atuo, mas que tenta trazer especialmente conteúdos que circulam no que tentei delimitar aqui como o campo feminista jovem autonomista, recusando, entretanto, a qualquer pretensão unificadora ou totalizadora do mesmo.

As reflexões que apresento foram frutas de muitas trocas, conversas, convivências e construções coletivas mergulhadas em muito afeto e muitos conflitos. O processo de construção micropolítica das amizades e de redes de coalizão entre feministas autonomistas, lesbofeministas, transfeministas, feministas negras, feministas antiespecistas, anarcofeministas, de diferentes gerações foi para mim a referência em termos de pedagogias da dissidência e articulação de saberes localizados.

3 Cissexismo foi um conceito cunhado pelo movimento trans como uma forma de descentralizar o grupo dominante, expondo-o como apenas uma alternativa possível e não a 'norma' contra a qual pessoas trans são definidas. O termo cisgênero foi utilizado pela primeira vez pelo ativista transexual Carl Buijs, e a teorização sobre cissexismo foi desenvolvida e popularizadas pelas transfeministas Emi Koyama (2006) e Julia Serano (2007). Uma pessoa cissexual ou cisgênerx é alguém que se identifica com o sexo/gênero que lhe foi biopoliticamente atribuído ao nascimento, desfrutando de diversos privilégios nos contextos sociais. Uma pessoa transsexual ou transgênerx é aquelx que vive e se identifica com um sexo/gênero diferente do que lhe foi biopoliticamente atribuído ao nascimento, sendo marginalizadas e sofrendo violências e silenciamento no regime cissexista biologizante e binário. É um conceito desessencializante pois retira do marco biológico a referência para a identificação sexo-genérica e a inscreve no plano politico: "Quando uso os termos cis/trans não é para falar sobre diferenças reais entre corpos/identidades/gêneros/pessoas cis e trans, mas sobre diferenças percebidas. Em outras palavras, apesar de não achar que meu gênero seja inerentemente diferente do de uma mulher cis, estou ciente de que a maioria das pessoas tendem a ver meu gênero de forma diferente (isso é, como menos natural/válido/autêntico) da que vêem o gênero de uma mulher cis." (tradução por Alice Gabriel retirada do blog da Julia Serano http://juliaserano.livejournal.com, disponível em: http://confabulando.org/kk2011/index.php/Main/WhippingGirlFAQPerguntasFrequentesSobreCisse xualCisgeneroEPrivilegioCis) 


\section{DECOLONIALIDADE, INTERSECCIONALIDADE ${ }^{4}$ E A CONSTRUÇÃO DE CONSCIÊNCIAS OPOSICIONAIS}

Seguindo as intuições de Mohanty (2004), nos dedicaremos às tarefas mais importantes dos feminismos decoloniais: fazer críticas aos feminismos hegemônicos e a criação de estratégias autônomas. Nos articularemos entre impulsos de oposição e táticas de construção de narrativas próprias. Yuderquis Miñoso (2009) se conecta a feministas decoloniais como Mohanty e Spivak na crítica à colonização discursiva dos feminismos ocidentais. Aponta como há uma colaboração entre os feminismos hegemônicos do norte e do sul que no espaço de luta transnacional ainda prevalecem epistemologias e práticas baseadas em ideologias etnocêntricas de classe, raça e heterosexualidade normativa.

Como forma de confrontar essa tendência hegemônica propomos recorrer à análise proposta por Chela Sandoval (2000) da construção de consciências oposicionais, buscando as tecnologias, metodologias e pedagogias de resistência desde subjetividades oprimidas e marginalizadas. Sandoval nos instiga à noção de consciência diferencial que caracteriza subjetividades situadas e subalternas agindo por posições táticas e autoconscientes. Encontramos nessa ideia uma proposta de interseccionalidade corporificada enquanto prática política autoconsciente de mover-se entre e através de vários tipos de ideologias oposicionais e estratégias políticas.

As formas de resistência oposicionais feministas latinoamericanas apontam para o desenvolvimento de tecnologias de autocuidado e saúde mental entre subjetividades desenvolvidas em condições de múltiplas opressões. São práticas psicológicas e políticas que envolvem sublinhar diferentes aspectos do self para atuar diante das organizações políticas e permitem realizar coalizões entre diferenças. Se há uma fluidez por entre os posicionamentos oposicionais diferenciais feministas, esta demanda leituras sobre o poder. Por isso se apoia nas construções coletivas de discursos e estruturas teórico-interpretativas

4 A noção de interseccionalidade foi elaborada a partir das críticas do feminismo negro a uma noção unificada de opressão sexista que se baseava nas experiências das mulheres brancas heterossexuais de classe média. O conceito foi difundido por Kimberlée Crenshaw (2002) segundo a seguinte definição: "Ela trata especificamente da forma pela qual o racismo, o patriarcalismo, a opressão de classe e outros sistemas discriminatórios criam desigualdades básicas que estruturam as posições relativas de mulheres, raças, etnias, classes e outras. Além disso, a interseccionalidade trata da forma como ações e políticas específicas geram opressões que fluem ao longo de tais eixos, constituindo aspectos dinâmicos ou ativos do desempoderamento" (CRENSHAW, 2002, p. 7). 
compartilhadas que permitem uma reconceitualização permanente da atividade oposicional como um todo.

As consequências radicais dessa perspectiva para a epistemologia feminista nos levam a incorporar a proposição de Crenshaw (2002) de pensar a centralidade do feminismo negro como ponto de vista para a análise crítica feminista interseccional. Nos sentimos convidadas a refletir profundamente a partir da elaboração de Patrícia Hill Collins (2002) sobre as contribuições específicas do pensamento feminista negro para pensar as matrizes de dominação que agem em nós. É nesse sentido que a pesquisa feminista deve ter como um de seus princípios a abertura à afetação pela dissidência e dissonância constitutivas das vivências de oprimidas, subaltenas, marginalizadas, cuja simples existência no mundo é vista como ameaça e tratada com violência de extermínio.

A proposta estético-analítica da pesquisa busca construir vieses decoloniais e antirracistas. Por isso, a delimitação do campo não passará pela reconstrução genealógica dos movimentos e ideologias políticas agrupados em torno dos significantes "feminismo", "autonomismo", "anarquismo". Tal enquadramento levaria necessariamente a um referenciamento centrado numa história eurocêntrica e branca, característica da maioria dos trabalhos acadêmicos da área.

Buscando contrapor-se a essa tendência, Francesca Gargallo (2006), em sua historiografia das ideias e práticas políticas feministas "nuestramericanas", argumenta a favor da análise das experiências de lutas de mulheres por sua autodeterminação como parte da história do feminismo. Mesmo que tal palavra não existisse ou não seja mobilizada pelas atoras, não consistiria num anacronismo ou imputação de significados inadequados. Sendo feita com o devido cuidado, essa análise permitiria o reconhecimento de resistências de mulheres que são invisibilizadas e apagadas da história, para a construção do feminismo latinoamericano enraizado politicamente.

Ochy Curiel (2007), em sua crítica à ausência de perspectivas feministas na maior parte dos trabalhos latinoamericanos sobre decolonialidade, propõe algumas experiências políticas como fundamento para os feminismos decoloniais: os feminismo negros e afrolatinos, feminismos indígenas e feminismos chicanos. Em consonância com Gargallo e Curiel, Jurema Werneck (2005) propõe partir da história de resistência das mulheres negras como referência para a ação política antirracista. A filósofa Sueli Carneiro (2005) nos chama atenção para a necessidade de enegrecer o feminismo, colocando a luta 
das mulheres negras no âmago do pensamento feminista, pois do contrário se torna apenas uma história centrada nas mobilizações de mulheres brancas de classe média, que nem mesmo endereçam as questões vividas pelas mulheres negras.

Yuderquis Epinosa Miñoso (2009) e Curiel (2007) explicitam também o caráter heterocentrado dos feminismos latino-americano. As autoras ressaltam a relevância histórica da crítica do feminismo autônomo como quebra com a criação de lógicas representativas não explicitadas nos movimentos e a profissionalização da militância, ambos com forte caráter elitista.

A ruptura político-ideológica com a institucionalização crescente dos movimentos feministas e sua subordinação às pautas de financiadoras internacionais foi mais abertamente enunciada em Sorata, em 1993, com a formação da coletiva "Las Cómplices" composta por feministas chilenas e mexicanas, como Margarita Pisano e Ximena Bedregal.

A publicação de manifestos feministas autônomos e a realização de encontros específicos do campo ao longo dos anos permitiu a emergência de diversos discursos e grupos de feministas autônomas, entre os quais gostaríamos de destacar a coletiva Mujeres Creando, formada por Maria Galindo (Argentina) e Julieta Paredes (Bolívia), e as afrolatinas Ochy Curiel e Yuderquis Espinosa-Miñoso. O Primeiro Encontro Feminista Autônomo, com o desafio de "Fazer Comunidade na Casa das Diferenças", se deu no México em 2009 e depois ocorreram diversos por toda latino-américa. Apesar dos diversos conflitos e rupturas ao longo da construção da história do feminismo autônomo latino-americano, e mesmo que não se possa falar de uma corrente única, podemos caracterizar objetivos, metodologias e tipos de organização. 


\section{ALGUMAS PRINCÍPIAS 5 FEMINISTAS AUTONOMISTAS JOVENS LATINOAMERICANAS}

Baseada no trabalho coletivo de sistematização e conceituação de princípias que considerávamos fundamentais na organização da AntiFest Suspirin Feminista ${ }^{6}$, incorporamos algumas delas como categorias analíticas na pesquisa pois representam pontos importantes de serem observados nos campos latinoamericanos. A partir de um extenso trabalho de campo em diversos encontros feministas (MARTELLO, 2015), pudemos delimitar melhor as propostas, dinâmicas de interação, conflitos e desafios dos feminismos jovens autonomistas:

a) autonomia, autogestão e façamos por nós mesmas

$\mathrm{O}$ ideário de autonomia consiste no recurso a si mesmas contrapondo-se à delegação a terceiros para garantia de que seus direitos sejam assegurados. Por isso, muitas das metodologias nos ambientes feministas autônomos são voltadas para saberes práticos direcionados ao cotidiano e à criação de uma cultura de autodefesa. Muitas das estratégias de resistência das mulheres ao longo da história podem ser associados a essa perspectiva, mas foi após a "democratização" de alguns países da América Latina e da entrada mais ampla de feministas nas políticas estatais que esse deixou de ser um viés predominante e passou a ser uma corrente específica.

5 Realizaremos nesse texto uma "guerrilha linguística" fundamentada na crítica feminista à concepção masculina hegemônica do conhecimento, que passa também pela linguagem, questionando o uso do masculino como universal. Rompendo com o sexismo linguístico, diversas grupas e encontras feministas passaram a utilizar os termos que denominam e identificam suas práticas no feminino. Criticando o binarismo linguístico, várias transfeministas propuseram diferentes alternativas para uma linguagem que contemplem as múltiplas identificações de gênero. A mais profícua de todas é evitar o uso de termos com marcação de gênero, mudando o tempo verbal ou escolhendo termos que são indefinidos quanto ao gênero. Na falta dessas opções, utilizaremos alternadamente o "e" ou o " $x$ ". Devido às críticas de transfeministas que afirmam que o " $\mathrm{x}$ " tende a cair também no universal masculino na leitura oral, em algumas ocasiões utilizaremos ambas o feminino e o $x$, para contemplar mulheres, lésbicas e trans.

6 O Antifest Supirin feminista foi um encontro ocorrido em 2014 em Belo Horizonte por uma confluência de feministas autonomistas da qual participo. O evento contou com cozinha vegana, shows, debates sobre transfeminismo, feminismo antiprisional, conversa sobre cabelo afro, binarismos, lançamento de zines, oficinas de autodefesa, gordofobia e cuerpa, FTM faça-vocêmesmx, brinquedas sexuais faça-você-mesmx, spanking, entre outras. "O Antifest é um suspirin feminista em meio à violência machista e às tretas da vida. É a tentativa de praticarmos juntas formas feministas de nos relacionar entre nós e construir uma zona de resistência autônoma feminista." (Suspirin Feminista, 2014, disponível em: http://suspirinfeminista.hotglue.me/) 
A autoidentificada corrente do feminismo autônomo surgiu nos anos 90, fazendo frente à institucionalização do feminismo, que se deu a partir de sua proximidade com o Estado, os governos, e a partir de sua própria estruturação na forma de organizações não-governamentais (também chamadas neogovernamentais).

En nuestra genealogía recogemos todas las formas de resisténcia activa de nuestras ancestras indígenas y afrodecendientes; el legado del feminismo radical de los años setenta; las experiencias tempranas de los grupos de autoconciencia; las prácticas del affidamento y de concesión de autoría creativa entre mujeres de las feministas italianas de la diferencia; el feminismo situado, descentrado y antirracista del movimiento de mujeres latinas, chicanas y de color en los EEUU que ha tenido su continuidad en Latinoamérica y el Caribe; los aportes de las lesbianas feministas en lucha contra el régimen de la heterosexualidad obligatoria opresivo para todas las mujeres; el reconocimiento de las mujeres como categoría política y no natural tal cual nos lo enseñaron las feministas materialistas; y, mucho más cercanas, nos sentimos herederas de esa parte de la generación de feministas de los setenta que a finales de los ochenta no estuvo dispuesta a abandonar sus aspiraciones de transformación radical de la realidad y anunció los peligros del nuevo pacto entre una parte importante del feminismo con la cooperación internacional, el sistema de Naciones Unidas, el Estado y sus instituciones. (Declaración Feminista Autônoma, 2005)

A corrente do feminismo autônomo se funda, portanto, na crítica radical ao que considera incoerências e armadilhas presentes no movimento, enuncia a autonomia como uma postura política no mundo manifesta na prática micropolítica cotidiana, e propõe a construção de espaços libertários e horizontais e que façam frente de forma integrada a todos os tipos de dominação e subordinação.

\section{b) organização entre mulheres, lésbicas e trans ${ }^{\star}$}

A construção de espaços políticos feministas sem a presença de homens cisgênero surge a partir de uma longa história de atuação em espaços mistos, nos movimentos sociais e espaços libertários, e inclusive no movimento LGBT (MONGROVIEJO, 2000), que mostrou que muitos dos padrões de socialização masculina se manifestam de maneira recorrente, especialmente o monopólio do uso da fala, que resulta na invisibilização das experiências e especificidades de mulheres, lésbicas, trans e intersexuais.

A tensão, muito recorrente, senão inerente à construção de espaços separatistas, se deve em grande parte a um desconhecimento de muitas 
feministas, ou pessoas que estão adentrando as redes e discursos do feminismo, da proposta política em que o separatismo está fundamentado e de sua importância na trajetória histórica no feminismo. O separatismo pode ser pensado como prática de distanciamento das instituições patriarcais e de construção de lógicas e espaços próprios, que escapem aos dispositivos de captura do heterossexismo, possibilitem a construção de vínculos de solidariedade, e favoreçam a formação da autoconciência, auto-organização e a construção de uma comunidade política entre feministas. É importante, nesse ponto, pensar sobre a persistente necessidade desses momentos para fomento de uma postura fundada na dimensão corpórea da experiência que condiciona perspectivas e lugares de enunciação.

\section{c) cuidada e apoia mútua}

Enquanto o cuidado com os homens e com os filhos consiste em um fardo patriarcal compulsório para as mulheres, cuidar-se entre feministas é uma ruptura com a competitividade e por isso é uma tendência antipatriarcal. Nesse sentido, é proposta a ideia de sororidade/irmandade a partir de uma perspectiva contingente, que possibilite em cada momento e espaço específico, enfrentar a inimizade patriarcal que impede a solidariedade entre congêneres e reforça eixos hierárquicos de dominação por questões classistas, racistas, sexistas e cissexistas.

Nos interessa observar, de maneira mais sistemática, quais têm sido as metodologias e pedagogias adotadas nos espaços feministas para lidar com a radicalidade da diferença real, criando respostas para os conflitos no momento em que eles acontecem, e que permitam fazer críticas sem perpetuar uma política de ruptura sumária ou a criação de inimizades. Trata-se de analisar as políticas de afeto, em que seja possível se afetar com as críticas e criar vínculos de afetividade que não sejam silenciadores das diferenças. Um exemplo de debate que têm se mostrado muito frutífero são as atividades que problematizam questões sobre consentimento e consenso.

\section{d) horizontalidade}

O ideal de horizontalidade não significa a ausência de conflitos, negociações identitárias e violência nesses contextos, mas sim a problematização das relações de poder internas que vão de encontro a uma ideia de solidariedade automática. Uma das maiores forças das propostas levadas a cabo nos encontros, festivais e outros espaços feministas autonomistas é o fato de que as atividades não têm caráter deliberativo, encerrando em objetivos imediatos 
(CARMO, 2013), transformações no nível da subjetividade e compartilhamento de saberes práticos voltados para ações cotidianas. Esse fator favorece relações menos hierarquizadas que não privilegiam apenas as pessoas com maior habilidade discursiva. Um aspecto que também merece ser ressaltado é a temporalidade dos processos, já que a qualidade dos diálogos e das trocas também depende das pausas que podem ser feitas para a compreensão, e é necessário respeitar os limites corporais. Em alguns encontros feministas autonomistas têm-se abandonado cada vez mais as programações massantes, para que maior preocupação seja o bem estar das pessoas que estão presentes.

\section{e) anticapitalismo, antiestado e seus aparelhos repressores}

O campo autonomista congrega principalmente feministas de orientação ideológica socialista libertária e anarquista, e por isso possui um viés fortemente anticapitalista e antiestado enquanto instituição mantida pela repressão militarizada. O autoritarismo militar representa, desde os anos 60, a mais alta expressão da opressão nos olhos das teóricas latino-americanas (ALVAREZ, 1990). Considerando que na maioria dos países da América Latina, mesmo após a "democratização" se manteve a economia política capitalista, extrema desigualdade social e o controle pelas forças militarizadas, em especial nas periferias e bairros populares, os feminismos autonomistas mantiveram sua desconfiança com relação a uma maior aproximação ao Estado. Percebendo a tendência de despolitizar a perspectiva de gênero nas políticas estatais e o recorrente silenciamento dos movimentos sociais, as feministas atuantes nesse campo chamam atenção para a importância de manter as políticas de solidariedade e de ações voltadas para a transformação da cultura machista.

\section{f) antietariasmos, antiadultocentrismo e conflitos geracionais}

Além de todas as discussões já apresentadas ao longo do projeto, seria importante ressaltar aqui a crítica a uma noção de etapismo evolucionista que perpassa a percepção de muitas feministas que acreditam que o ativismo jovem seria seguido de outros tipos de ativismo "mais maduro". Essa ideia invisibiliza as diferenças nas perspectivas e propostas ideológicas que caracterizam esses feminismos, subvalorizando algumas formas de feminismo, em especial os autonomistas. Já no campo autonomista, as jovens criticam a tentativa de se fundar uma narrativa e história única que privilegia certas atoras, em especial as feministas com maior trajetória de movimento.

\section{g) antilesbofobia}

A presença histórica de lésbicas no movimento feminista ao longo de toda sua 
história não foi suficiente para impedir que se hegemonizasse no campo um discurso heterocentrado que invisibiliza a existência lésbica, ocultando a condição estruturante instaurada pela heterossexualidade obrigatória como regime político que produz a subordinação das mulheres (RICH, 2010) e o contrato social heterossexual como mecanismo de dominação masculina. $\mathrm{O}$ feminismo autônomo, apesar de ter sido construído por grupos e coletivos formados por um número significativo, senão majoritário, de lesbofeministas, nem sempre consegue escapar do discurso heterocentrado. A invisibilidade das experiências lésbicas está diretamente relacionada à manutenção da concepção, por grande parte das feministas, da lesbianidade como uma preferência ou opção sexual. Essa ideia ignora a análise feita por Rich de que num sistema em que a heterossexualidade é imposta para as mulheres como uma forma de controle de seus corpos e de sua existência, ela não pode ser pensada em termos de escolha. Nesse sentido, a proposição de espaços específicos para compartilhamento de experiências entre lésbicas, têm se mostrado não apenas como um importante momento de construção da "autoconsciência" entre lésbicas, mas também como uma fonte de tensionamento com o pensamento heterocentrado nos encontros, espaços e discursos feministas.

A presença de lesbofeministas problematizou a forma como os espaços políticos feministas são concebidos como espaços de/para/entre mulheres e, num tráfico crítico e dialógico com a teoria de Monique Wittig (2010), questionou a pressuposição de que lésbicas são mulheres. Havendo várias lésbicas que não se identificam como mulheres no movimento, e que reivindicam que tal posicionamento político seja respeitado, os encontros passaram a ser propostos e proclamados como encontros entre "mulheres e lésbicas". Tal mudança expressou uma abertura ao questionamento de "a mulher" como sujeita única ou principal do feminismo e iniciou um processo de reconhecimento da importância de sujeitas que não se identificam como mulheres para o feminismo.

\section{h) antitransfobia}

O debate sobre a participação de pessoas trans no feminismo se coloca como uma questão no campo há mais de duas décadas e têm se manifestado de diferentes formas nas diferentes regiões geopolíticas, espaços e correntes do feminismo, mas sempre de maneira muito tensa e dolorosa, especialmente para as pessoas trans. De acordo com Emi Koyama (2006), o debate sobre a "inclusão" das pessoas trans no feminismo parte da pressuposição de que todas as mulheres possuem experiências similares, o que subestima as formas de 
violência e opressão entre feministas e desconsidera a crítica do feminismo negro e lésbico, que explicita as diferenças de privilégio e poder entre as mulheres. Parte, portanto, de uma lógica que desconsidera a efetiva interseccionalidade que caracteriza as diferentes experiência subjetivas subalternas.

O aporte teórico do transfeminismo consiste na conceitualização do cissexismo enquanto um sistema que impõe uma divisão binária dos gêneros e uma coerência entre corpo, identidade de gênero e orientação sexual, e que privilegias as pessoas cisgênero e patologiza e marginaliza as pessoas trans. A restrição destas no feminismo seria, portanto, baseada no privilégio cis.

\section{i) antirracismo}

Apesar de ter sido uma questão colocada de maneira contundente pelas feministas negras ao longo de toda a história de luta antimachista, o racismo permanece um tema muito pouco abordado. Havendo ainda hoje uma predominância branca nesses espaços, o racismo se mostra na ausência da temática racial que invisibiliza a branquitude e seus privilégios. As feministas negras recorrentemente atestam que sua presença nos espaços é invisibilizada em frases que ressaltam apenas a ausência de negras ou falam de sua opressão de maneira distanciada, como se os privilégios das mulheres brancas também não fizessem parte da dinâmica racial. Além disso, se sentem expostas com frequência quando são compulsoriamente chamadas para falar sobre sua condição, em uma tentativa de criar representatividades de uma categoria, ou para educar as feministas brancas sobre as práticas racistas perpetuadas. Ainda está para ser incorporada as críticas das ativistas-teóricas negras para de pensar um feminismo antirracista que não seja paternalista e silenciador.

\section{j) antiespecismo}

O antiespecismo é uma luta trazida principalmente nesse campo pelas feministas veganas, ou seja, pessoas que não consomem nenhum produto de origem animal ou que envolvam algum tipo de exploração animal, seja ela humana ou não-humana (CARMO, 2013). Na perspectiva vegana, o especismo é a ideia de que os animais humanos são superiores aos animais não humanos e por isso podem escravizar, explorar, domesticar, matar e dispor de seus corpos como bem entender. É baseada no ideal antropocêntrico de que o homem deve se apropriar da natureza de maneira indiscriminada devido a sua suposta racionalidade ou faculdades mentais complexas. Contrapondo-se a pecuária extensiva, à monocultura agrícola, à indústria da carne, lácteos, vivissecção e 
testes, as feministas veganas consideram que a libertação animal em geral é indissociável da libertação humana.

A relação entre feminismo e vegetarianismo é próxima desde o início do século XIX, quando se tem registro dos primeiros grupos que articulavam essas duas questões (CARMO, 2013). Entretanto esse debate tem ganhado muito mais força no campo, em especial devido à sua difusão na internet. As feministas veganas estabelecem uma relação entre a mercantilização dos corpos das mulheres e dos corpos de animais não-humanos, apontando a conexão entre masculinismo e carnivorismo. Nos espaços de sociabilidade feminista a questão é colocada principalmente nos momentos de alimentação e comensalidade, quando muitas vezes surgem conflitos e bons debates sobre a origem da comida, o sofrimento animal e a reprodução da exploração e das opressões em nossas práticas cotidianas.

\section{RESISTÊNCIAS FEMINISTAS ANTICAPITALISTAS E AUTONOMISMOS LATINO-AMERICANOS}

Para entender a relação entre os feminismos autonomistas e os socialismos e anarquismos na América Latina é importante refletir também sobre como o conceito de autonomia, e outras noções como a de subalternidade e antagonismo dialogam teoricamente com as diferentes vertentes marxistas. Massimo Modonesi (2010) faz uma análise sobre as relações entre sujeito e ação política, abordando primeiramente o aporte de Gramsci para pensar o processo de subjetivação subalterna enquanto experiência de subordinação em relações de dominação. Para o autor, o desenvolvimento do conceito é fundamental para compreender a experiencia no contexto da exploração não apenas sobre o proletariado, mas sobre outros setores marginalizados na sociedade. Entretanto, entende que, enquanto sobrevivência à margem das elites, o lugar da subalternidade por si não pode realizar seu potencial emancipatório pois implica necessariamente em algum tipo de dominação ou opressão que impede a autonomização plena.

O autor também avalia cuidadosamente a noção de subjetivação antagonista aportada por Antonio Negri, pensada enquanto experiência de insubordinação, luta e rebelião diante de uma situação de conflito, abordando suas potencialidades e os perigos da generalização do antagonismo dissociado da experiência de opressão. Modonesi aponta como a ideia de autonomia 
aparece principalmente de duas formas: como independência social, política e ideológica do sujeito-classe; e como emancipação entendida como processo, prefiguração ou modelo de sociedade. As formas de subjetivação autonomistas se desprendem das práticas e experiências de liberacão e emancipacão forjadas no diálogo entre espontaneidade e consciência.

O teórico articula temporalidades presentes e futuras na prefiguração, aproximando-se da ideia de comunismo enquanto método e conteúdo libertário e democrático, conjugando utopias procedimentais e substanciais no qual a classe se forma na luta. As experiências autonômicas e autogestionárias seriam, portanto, o próprio processo e experimentação da ruptura política. Pensada no contexto latinoamericano também como autodeterminação dos povos e autonomias locais, enfatiza a luta cotidiana enquanto coordenação espontânea de atos políticos conscientes de uma coletividade, recuperando as noções trabalhadas por Rosa Luxemburgo e pelo conselhismo.

Modonesi (2010) critica, entretanto, tanto as concepções do grupo Socialismo e Barbárie, quanto as tendências anarquistas sobre autogestão, vistas por ele como desvio de categorias centrais na análise marxista. Contrapõe-se também ao autor John Holloway (2001), apesar de reconhecer a importância de suas reflexões em torno do poder sobre como subordinação e do poder fazer como não subordinação. Defendendo que subjetividades anticapitalistas são forjadas em contextos de conflito e crise, o autor ressalta a autonomização enquanto processo.

Holloway (2001), em seu "Mudar o mundo sem tomar o poder", ressalta as formas de antipoder ou contrapoder, enquanto estratégias de dissolução do poder como horizonte de luta política. $\mathrm{O}$ autor se inspira e apoia a luta zapatista, concebida enquanto caminhar perguntando, uma reflexão e autocrítica permanente. A partir da noção de política afetiva impulsionada por Raul Zibechi, Holloway (2001) sugere que as formas de solidariedade, amizade, amor, reconhecimento mútuo e dignidade podem criar espaços apesar e para além do capitalismo, retirando do enfoque a necessidade de constituição da contra-hegemonia através da disputa do Estado.

Patrick Gun Cuninghame (2010), em um texto sobre autonomia e autonomismo social latinoamericanos, relaciona processos no México, Bolívia, Brasil e Argentina, como alianças híbridas de antagonismos e movimentos sociais. Em convergência com o teórico uruguaio Raul Zibechi, o autor situa como bases do autonomismo latinoamericano o neozapatismo e a Outra Campanha no México, os movimentos indígenas na Bolívia, o movimento de 
sem terras no Brasil e os piqueteiros, as fábricas recuperadas e as assembleias de bairro argentinas.

Cuninghame considera o conceito de multidão proposto por Negri como central para a teoria política autonomista, considerando uma figura coletiva e diversificada que responde à necessidade de se pensar uma classe antagônica em mudança constante. Criticando a ideia de revolução como tomada do poder estatal e as alianças com as burguesias nacionais no que chamam "reformismo sem reformas", os autores recebem duras críticas dos teóricos das esquerdas nacionalistas partidarizadas. Pensada como alternativa às noções de povo e proletariado, Negri incorpora a ideia do capitalismo como cognitivo e biopolítico que se apropria também do trabalho imaterial e afetivo.

Destacando o caráter conflituoso entre as esquerdas nacionalistas e os projetos autonomistas, Cuninghame sugere que mesmo estando articuladas em ações em diversos momentos histórico-políticos, muitas vezes seus projetos são contraditórios e se distanciam:

No obstante, hay señales importantes de tendencias en la cultura política mexicana y latinoamericana hacia el horizontalismo y localismo descentralizado combinado con el globalismo anticapitalista antagónico y la democracia directa asambleísta del autonomismo, alejándose así del autoritarismo, verticalismo y estadocentrismo del nacionalismo de izquierda. Uno de los ejemplos más importantes desde 2006 ha sido el movimiento oaxaqueño autónomo, la Asamblea Popular de los Pueblos Oaxaqueños (APPO). El proyecto del primero es la autonomía, no solamente de clase frente al capital, también de los distintos sectores de la clase entre sí (mujeres, indígenas, jóvenes, etcétera) y la dispersión del poder en la sociedad en lugar de su concentración en el Estado. El proyecto del segundo es ganar el poder centralizado por medio de la hegemonía políticocultural y la toma del poder estatal. En América Latina estas dos tradiciones políticas están separándose otra vez después de un breve periodo de alianza a partir de la experiencia de los foros sociales mundiales y regionales y del movimiento no global desde Seattle en 1999 hasta Cancún en 2003. (Cuninghame, 2010, p. 161)

Em sintonia com a reflexão política desses teóricos, Janice Tirelli (2014) e Igor Oliveira (2012) localizam no levantamento zapatista de 1994 um marco constitutivo do autonomismo latinoamericano. Dando materialidade aos sonhos de resistência global altermundialista desde as experiências propriamente latinoamericanas, o zapatismo se torna uma referência não apenas para ideias de organização e transformação autonomistas em Abya Yala, mas em todo o mundo, mobilizando ações de solidariedade translocal em uma 
configuração nunca antes dimensionada pelas esquerdas tradicionais.

O movimento de resistência indígena autonomista impulsionado desde Chiapas e Oaxaca, articulado com diversos outros movimentos como o Movimento dos Trabalhadores sem Terra no Brasil, o movimento de agricultores da Índia e formações ecléticas de anarquistas, ecologistas e clubbers do Reclaim the Streets inglês, entre outros, criaram a Ação Global dos Povos, que impulsionou dias de ação globais simultâneos em diversas cidades do globo como forma de enfrentamento ao capitalismo neoliberal (OLIVEIRA, 2012).

Segundo informações obtidas em seu sítio eletrônico, a Ação Global dos Povos contra o Comércio "Livre" e contra a Organização Mundial do Comércio, também conhecida pela sigla AGP, surgiu em fevereiro de 1998, durante uma reunião de diversos movimentos de todos os continentes em Genebra, Suíça, como uma coordenação mundial de resistência contra o mercado globalizado. Sua primeira reunião aconteceu também em Genebra em maio de 1998, simultaneamente a uma reunião da Organização Mundial do Comércio (OMC).

Houveram também outras grandes conferências na Índia e na Bolívia, em 1999 e 2001, respectivamente, em que se estruturaram e reestruturaram seus cinco princípios básicos, seu manifesto e seus princípios organizacionais. Nesses documentos, articulam uma série de opressões e explorações do trabalho, de gênero (incluindo orientação sexual), raça e etnia e questões ecológicas, tecnológicas, de migrações, saúde e educação. Autointitulando-se anticapitalista e antiglobalização, essa rede direciona sua luta ao sistema capitalista e a diversas formas de opressão, tendo, portando, um viés não apenas redistributivo. Enquanto um movimento radical, reivindica uma sociedade fundada em outras bases, sem qualquer tipo de dominação.

Essa articulação, que atua através da ação direta, coordenou os chamados dias de ação global, em que manifestações simultâneas em diversas partes do mundo acabam por ganhar espaço nas mídias de massa e atingir a opinião pública internacional. As manifestações ocorrem, em sua maioria, em dias de encontros de organizações internacionais como o G8, FMI, Banco Mundial, Fórum Econômico Mundial e principalmente a OMC, com maior força na cidade onde estão sendo realizados os encontros, mas também em muitos lugares do mundo simultaneamente.

Sua maior ação foi ente 1998 e 2001, quando foram realizados os maiores dias de ação global, que geralmente eram nomeados pela data da manifestação. $\mathrm{Na}$ maioria das vezes, as manifestações conseguem impedir, atrapalhar ou ao menos influenciar as negociações e decisões dos encontros. A mais famosa de 
todas, N30, ocorrida durante a rodada do milênio da OMC em novembro de 1999, que também ficou conhecida como a Batalha de Seattle, agregou diversos movimentos entre ecologistas, ongs, sindicalistas e outros ativistas, entre pacifistas ou não, totalizando aproximadamente 50.000 pessoas nas ruas de Seattle. Em setembro de 2000 o S26, um dos maiores dias de ação global, mobilizou um número enorme de pessoas em mais de 40 países.

No Brasil, sua maior atividade foi em São Paulo, também na época de 1998 a 2001, sendo a do A20 uma das maiores. Houve muitas manifestações, mas, assim como em todos os outros lugares, as repressões policiais eram fortíssimas. Além disso, segundo participantes do movimento, também houve perseguição, por parte da polícia, de alguns articuladores da rede, o que também dificultou a ação dos grupos que coordenavam a AGP no Brasil, que hoje se encontra em baixa atividade. Em diversos lugares do mundo, no entanto, ainda se encontra em atividade, tendo realizado, entre outras, manifestações no encontro do G8 no Japão em julho de 2008. Mesmo que não tenha se mantido ativa no Brasil, a AGP influenciou profundamente os movimentos sociais e de protesto e ainda influencia nos dias de hoje.

É importante ressaltar que no plano latinoamericano, as mobilizações impulsionadas pela AGP conseguiram frear os avanços das negociações da ALCA, especialmente pela adesão popular massiva nos protestos. Juntamente com as articulações do Fórum Social Mundial, mobilizações de movimentos campesinos, de mulheres, de resistência negra e indígena, entre outros, esses movimentos puderam afirmar uma contraposição à máxima neoliberal de que "não há outra alternativa".

A literatura sobre movimentos sociais nos indica uma relação intensa entre as subculturas juvenis radicais e as experiências de militância autônoma anticapitalista. $\mathrm{O}$ autonomismo compreende uma diversidade de movimentos de moradia, ocupações urbanas, ecologismos, movimentos anticapitalistas e altermundialistas, antinucleares, antiguerra e antimilitaristas, antifascistas, antiautoritários, antirracistas, antixenofobia e por direitos de imigrantes e refugiados, além de feministas, minorias étnico-raciais, grupos de dissidência sexual e de gênero, entre outros. É característica dos autonomismos essa formação heterodoxa e a diversidade ideológica, mas com uma forte crítica à noções de vanguardismo e ao burocratismo dos partidos, que caracterizam a maior parte da esquerda socialista.

Análises como a de Melucci (1997) nos mostram que o autonomismo não é uma cultura exclusivamente juvenil, abarcando pessoas de diversos 
pertencimentos geracionais, e que questiona a temporalidade moderna ocidental como um todo. Para o autor, esses movimentos problematizam o poder social exercido sobre o tempo através de sua própria ação que cria novos códigos culturais através da vivência prática, no presente, de experiências coerentes com suas proposições ideológicas.

Halberstam (2005) critica a dicotomia entre juventude e vida adulta hierarquicamente inscrita na lógica heteronormativa da família nuclear reprodutiva como um componente central dos códigos dominantes da temporalidade capitalista. Especifica a problematização do poder sobre o tempo e a proposição de modos de vida alternativos nas proposições feministas e queer como sendo as suas características com o maior potencial transformador. Para a/o autora/o a subversão ou deslocamento dessas normas nos exige a criação de redes de afinidade e amizade e de imaginários políticos comuns. A criação de espacialidades e temporalidades próprias nos permitem o apoio necessário para sobreviver no mundo hostil às existências subalternas.

A subjetivação política em que os autonomismos latinoamericanos são forjados passa, portanto, pela articulação de várias posições críticas desde a subalternidade, constituindo-se desde o antagonismo ao neoliberalismo enquanto forma colonizadora de dominação. Entretanto, ao invés de se basear na ideia de soberania ou autonomia nacionalista-estatal, o autonomismo se fundou numa constelação de alternativas de apoio mútuo translocal.

\section{FEMINISMO AUTÔNOMO LATINOAMERICANO E AUTONOMISMO NOS FEMINISMOS JOVENS}

A noção de autonomia no feminismo se coloca como oposta à noção liberal de liberdade individual, que sempre foi pensada e proposta em padrões masculinos de vida e quase sempre garantida exclusivamente para homens brancos heterossexuais proprietários, colocando mulheres, crianças, negros e negras, e animais não humanos como suas propriedades (CARMO, 2013). A autonomia para as mulheres, lésbicas e trans implica autodeterminação e capacidade de tomar decisões sobre o próprio corpo, a inviolabilidade e integridade das corpas assegurada pelo direito à resistência e à autodefesa.

A autonomia feminista pode ser pensada também como autokoinonia, como nos frisa Marta Amanda Fontela (2007) retomando da discussão de Sarah L. Hoagland, conectando o próprio com a comunidade. É 
nessa relação com outras, na comunidade feminista, que nos é possibilitado formar as nossas consciências críticas, fazer escolhas e atuar levando em conta as necessidades e percepções des outres. Os vínculos aqui são os que nos permitem a transformação da realidade e a vivência da autonomia e da autodeterminação.

A ênfase na autonomia está ligada a uma concepção de poder e de transformação que vê a mudança cultural e a micropolítica como fundamentais e urgentes. A autonomia aqui significa "atuar levando em conta os próprios valores e interesses e definir a realidade a partir de si mesmas, contestando os contextos de opressão que desvalorizam os grupos oprimidos. Supõe analisar, revalorizar, reivindicar as próprias experiências, prescindindo dos valores e discursos masculinos como pontos de referência, para poder nomear-se e autodefinir-se" (FONTELA, 2007).

O debate sobre a criação de espaços específicos feministas sempre esteve muito interrelacionado com o enfrentamento ao machismo nos movimentos sociais e nos partidos de esquerda. A própria noção de autonomia sempre enfatizou a não subordinação aos movimentos políticos mistos hegemonizados pelos homens cisgênero, que consideram as questões e a atuação políticas feministas como "secundárias", enquanto reproduzem padrões machistas de funcionamento. Atualmente, diversos movimentos feministas, como a Marcha Mundial de Mulheres, trazem a proposta da auto-organização como fundamental para as lutas contra o patriarcado.

A maioria das concepções de auto-organização, entretanto, mantém a pressuposição de que existe uma "luta geral" e uma "luta específica" feminista. Essa ideia tende, mais uma vez, a reproduzir a possibilidade de uma "luta geral" - universal - cujos princípios não tenham sido completamente reformulados a partir das críticas feministas e que não incorpora de maneira consistente, ou no mínimo paritária, as contribuições de mulheres, lésbicas, negras, indígenas. Sem essa feminização, descisheterossexualização e descolonização das perspectivas nos contextos de lutas políticas, as utopias, propostas, métodos, pedagogias de transformação podem vir a reproduzir os tradicionais modos de viver e do agir patriarcais, masculinos, brancos e heterossexuais.

A participação em espaços feministas tem o potencial de empoderamento, oferecendo uma crítica mais radical aos modos machistas de funcionamento nas diversas esferas sociais e políticas nas quais participamos. Muitas feministas passaram a se identificar mais com o campo autonomista devido a uma exaustão com o enfrentamento de processos patriarcais nos espaços mistos de 
movimentos sociais e partidos. Esses enfrentamentos continuados as faziam ter que estar a todo o tempo confrontando, tentando convencer da importância a respeito das questões feministas, "disputando terreno" para poder participar, ser ouvida, de ser chamada a educar os homens e ser criticada por ser muito radical e pouco "femininamente conciliadora".

A principal forma de organização feminista para as feministas autônomas são os pequenos grupos de autoconsciência, que consiste em escutar-se entre mulheres nomeando sentimentos e experiências individuais para descobrir-se na experiência da outra, passo importante para o processo de tomada de consciência da opressão (GARGALLO, 2006, p. 60). Karla Adrião (2008) também ressalta a importância desses grupos de reflexão nos quais, com a socialização da vida privada, a percepção da experiência como destino imutável é desfeita, recriando os liames que evidenciam a opressão e a exploração das mulheres.

Retomando a discussão sobre os grupos de reflexão e autoconsciência como uma estrutura organizacional básica do movimento feminista, Adrião ressalta que a transformação social vigente se daria a partir do próprio grupo, via alteração de comportamentos e posturas no cotidiano de cada uma. Essa ideia também é compartilhada por Itacarambi:

La autoconciencia feminista se relaciona intimamente a la creación de una gramática própria, que uniera lo existencial y lo político desde la experiencia concreta. Y la unión de essas dos dimensiones, cuya separación incorpora las intencionalidades sistémicas asociadas al dominio patriarcal (Kirkwood, 1983), es lo que le ofrece una textura especial y le hace tan poderosa, en los términos de la creación de referenciales que escapan a la lógica de dominación patriarcal. El resultado ha sido que les ha permitido a las mujeres vivir y pensar por si mismas, fuera de las definiciones dominantes, de ser sujetas políticas de una historia própria. Fue, por lo tanto, una metodología inventada para poner en práctica la reinvención de lo político y encarnar el puente entre teoría y prática. (ITACARAMBY, 2012, p. 129)

Esse "espaço próprio" criado pelas mulheres, em oposição às formas masculinas de se organizar e fazer política, é caracterizado pela horizontalidade e pelo descentramento. Refletindo sobre os significados das práticas de poder e de política, as práticas de autoconsciência são baseadas na autonomia do movimento, no respeito à palavra de cada uma, na não delegação de representação e de poder e na exigência do respeito às diferenças, constituindose de forma rizomática e permeando molecularmente as sociedades com os 
discursos feministas contra a opressão das mulheres.

A apoia mútua é uma proposta muito presente nos meios anarquistas e autonomistas, tendo forte influência da tese de Kropotkin (2009) sobre a ajuda mútua como principal fator de sobrevivência e bem estar de um grupo - e não a competição, como propunham os darwinistas sociais. Hoje em dia a expressão é utilizada de maneira ampla no meio para designar as formas de reciprocidade e solidariedade entre sujeitxs marginalizadxs e oprimidxs em contextos de resistência, subversão e transformação social, tendo também sido incorporado nos feminismos jovens autonomistas.

A "cuidada" seria a dimensão afetiva necessária para os vínculos anticisheteropatriarcais. Se o cuidado com os homens é uma exigência compulsória do patriarcado sobre as mulheres, o cuidado com/entre mulheres, lésbicas e trans nos permite romper com a inimizade patriarcal. "Cuidada" seria importante nas políticas feministas de coalizão porque permitiria fazer críticas sem eliminar de vez a possibilidade de construção conjunta. Seria, portanto, uma forma de pensar pedagogias feministas de combate às opressões. Cuidada e ajuda mútua necessitam de uma construção de afinidade, que se dá na participação e nos encontros em espaços de incidência social, em práticas coletivas de autoconsciência e autoconhecimento.

O feminismo autônomo, através da radicalização da proposta de que "o pessoal é político", também se pensa como uma transformação do aqui e agora, ressignificando os processos subjetivos e implicando numa mudança na vida e nas relações íntimas. É nesse sentido que Julieta Kirkwood (1987) argumenta que o feminismo é uma ideia de revolução "total" e ela é experimentada "agora", pois mesmo que dure alguns instantes, deixa sua inscrição na história. A temporalidade revolucionária do feminismo é, assim, o presente. Articulando ética e metodologia, o feminismo autônomo propôs que os meios não podem ser separados dos fins, que o traçar de rumos deve coincidir com os rumos, que o sonho e a vigília devem andar de mãos dadas (ITACARAMBY, 2012).

É característica dos dois campos, e portanto também das interseções que constituem os feminismos autonomistas, a adoção de políticas prefigurativas, ou seja, modos de organização e táticas que reflitam o futuro da sociedade que se busca, numa ética da ação. Essa noção está correlacionada portanto à ação direta que não busca mediações, mas sim respostas a situações concretas através dos meios disponíveis. A prática da autodefesa seria uma forma de ação direta e ao mesmo tempo uma tecnologia de construção corporal que permitiria a resistência e a sobrevivência de grupos subalternos. 
Outra característica definidora do campo é a a busca pela horizontalidade e a contestação de todas a hierarquias sociais. Nesse campo de discussão, a crítica dos feminismos autônomos, anarcofeminismos, feminismos jovens, negros, lésbicos, transfeminismos, ecofeminismos, feminismos descoloniais, comunitários, gordos, indígenas, periféricos, populares, problematizam as relações de dominação e subalternização entre feministas. O enfrentamento a essas desigualdades é o maior desafio às práticas feministas para a construção de um feminismo interseccional (CRENSHAW, 2002), ou seja, que realmente articule de maneira substantiva essas posições de sujeito através das vivências materiais e corporais.

Por fim, nos parece importante pensar o apoio mútuo a partir da construção de afinidade política através da afetividade, da amizade e pela afetação corporal produzida no compartilhamento de experiências e vivências subalternas. Esse processo de afetação pelos sentidos compartilhados seria condição necessária para a ação política pensada numa perspectiva feminista autonomista.

Diversos autores como Scott (2014) e Bey (1990) nos apontam para a importância da criação de formas cotidianas de resistência, discutindo os aspectos subversivos de práticas de sobrevivência de grupos subalternos. A proposta teórico-metodológica da pesquisa consistiu então em analisar a criação coletiva de tecnologias de resistência psíquico-políticas que possibilitem a construção coletiva de pedagogias translocais (ALVAREZ, 2014) de difusão de espacialidades e temporalidades feministas alternativas à lógica opressora do sistema heteropatriarcal racista.

Nos questionamos, portanto, em que medida está sendo possível a construção de espaços, relações, culturas e tecnologias de resistência micropolíticas cotidianas que garantem ações políticas comuns e permitam o apoio mútuo em termos sociais, afetivos e psíquicos entre feministas jovens autonomistas? Estariam as diferenças entre posicionamentos de sujeito marcadas por privilégios e subalternidades ainda impossibilitando uma interlocução teórico-política aprofundada?

É notável no campo que, apesar da permanência de pressupostos éticos e ideológicos - ação política fundada no apoio mútuo e temáticas antiautoritárias - houve uma profunda modificação no campo do feminismo autonomista. Essas transformações teriam sido provocadas pelos questionamentos de relações de poder e privilégio e deslocamentos de perspectivas advindo de feminismos lésbicos, trans, negros, jovens e gordos, que podem ter possibilitado 
a reconfiguração das questões caras ao autonomismo e ao feminismo.

Tal reconfiguração possivelmente tensionou o campo em direção a uma perspectiva mais interseccional capaz de contemplar e fornecer recursos psíquicos, sociais e políticos para a resistência e ação coletiva entre feministas autonomistas. Como proposta política forjada especificamente no contexto latinoamericano, consistiria em uma contribuição própria dos feminismos autonomistas da região, uma proposta decolonial, ao subverter os fluxos hegemônicos de teorias e práticas políticas.

Como contribuição às reflexões feministas autônomas e decoloniais latinoamericanas defendo a importância de debatermos formas de organização e ação política de inspiração autonomista para sermos capazes de enfrentar simultaneamente as distintas facetas da ofensiva neoliberal do capital e do autoritarismo estatal que permaneceram e permanecem mesmo em governos de esquerda e socialistas na América Latina. Defendo uma visão de autonomia como uma forma de existência contra a dominação, uma ética do fazer, ser o que se pode fazer, que implica necessariamente uma afetação por experiências compartilhadas, e que nos exige deslocar de nossas zonas de conforto e privilégios e buscar alianças a partir de nossas experiências de resistência política.

\section{REFERÊNCIAS}

ALVAREZ, Sonia. Para além da sociedade civil: reflexões sobre o campo feminista. Cadernos Pagu. São Paulo, n. 43, 2014, p. 13-56.

. Encontrando os feminismos latino-americanos e caribenhos. Rev.

Estud. Fem., Florianópolis, v. 11, n. 2, Dec., 2003, p. 541-575.

ANZALDÚA, Gloria. Borderlands: la frontera. San Francisco: Aunt Lute Books, 1999.

BEY, Hakin. Zona autônoma temporária. Porto Alegre: Deriva, 2010.

COSTA, Claudia de Lima; ALVAREZ, Sonia E. Translocalidades: por uma política feminista da tradução. Rev. Estud. Fem., Florianópolis , v. 17, n. 3, Dec. 2009 .

COSTA, Claudia de Lima. Equivocação, tradução e interseccionalidade performativa: observações sobre ética e prática feministas descoloniais. In: 
BIDASECA, Karina et alii (ed.). Geneologías e Memorias Poscoloniales en América Latina: Escrituras fronterizas desde el Sur. Buenos Aires: Ediciones Godot, 2014.

COLLINS, Patricia Hill. Black feminist thought: Knowledge, consciousness, and the politics of empowerment. New York: Routledge, 2002.

CRENSHAW, Kimberlé. Documento para o encontro de especialistas em aspectos da discriminação racial relativos ao gênero. Rev. Estud. Fem., Jan 2002, vol.10, no.1, p. 171-188.

CUNINGHAME, Patrick. Resistiendo al imperio: Autonomía, autonomismo y movimientos sociales latinoamericanos. Veredas, v. 11, n. 21, p. 149-166, 2010.

CURIEL, Ochy. Crítica poscolonial desde las prácticas políticas del feminismo antirracista. Nómadas, n. 26, 2007, p. 92-101.

CURIEL, Ochy; FALQUET, Jules; MASSON, Sabine. Feminismos disidentes en América Latina y el Caribe. Nouvelles Questions Féministes, v. 24, n. 2, 2005.

DE LIMA BONETTI, Alinne. Etnografia, gênero e poder: Antropologia Feminista em ação. Mediações-Revista de Ciências Sociais, vol. 14, n. 2, 2009. DE SOUSA, Janice Tirelli Pontes. Os jovens anticapitalistas e a ressignificação das lutas coletivas. Perspectiva, v. 22, n. 2, p. 451-470, 2004.

ESPINOSA DAMIÁN, Gisela. Cuatro vertientes del feminismo en México. México: UAM Xochimilco, 2009.

FALQUET, Jules. Las «Feministas autónomas» latinoamericanas y caribeñas: veinte años de disidencias. Universitas Humanística, n. 78, 2014, p. 39-63.

FRASER, Nancy. Re-framing justice in a Globalizing World. In Anales de la Cátedra Francisco Suárez. Serie III. p. 89-106, 2005.

GARGALLO, Francesca. Ideas Feministas Latinoamericanas. 2a ed. México: Universidad Autónoma de la Ciudad de México, 2006.

HALBERSTAM, Judith. In a Queer Time and Place: Transgender Bodies, Subcultural Lives. New York: New York University Press, 2005.

HOLLOWAY, John. Doce tesis sobre el antipoder. Em: COLECTIVO SITUACIONES et al. Contrapoder. Una introducción. Buenos Aires: De mano 
em mano, 2001.

ITACARAMBY, Taís. "Si nos tocan a una nos tocan a todas". Feminicidio en singular, lucha en plural: Estudio de caso del asesinato de Alí Cuevas Castrejón y de la colectiva que lleva su nombre. Mexico: Centro de Investigaciones y Estudios Superiores en Antropologia Social, 2012.

KIRKWOOD, Julieta. Feminarios. Santiago de Chile: Documentas, 1987.

MARQUES, G. M. e PEDRO, Joana M. O feminismo Riot: geração e violência. Labrys. v. 22, p. 1-15, 2012.

MIÑOSO, Yuderkys Espinosa. Etnocentrismo y colonialidad en los feminismos latinoamericanos: complicidades y consolidación de las hegemonías feministas en el espacio transnacional. Revista venezolana de estudios de la mujer. vol. 14, no 33, p. 37-54, 2009.

MELUCCI, Alberto. Juventude, tempo e movimentos sociais. Revista Brasileira de Educação, n. 6, 6-14. 1997.

MODONESI, Massimo. Subalternidad, antagonismo, autonomía: marxismos y subjetivación política. Buenos Aires: Clacso, 2010.

MOHANTY, Chandra Talpade. Feminism without borders: Decolonizing theory, practicing theory. Durham \& London: Duke University Press, 2004.

NASCIMENTO, Tatiana. Mas como toda opressão está conectada? Seminário Internacional Fazendo Gênero 10 (Anais Eletrônicos), Florianópolis, 2013.

OLIVEIRA, Igor Thiago Moreira. Uma “praia” nas Alterosas, uma “antena parabólica” ativista: configurações contemporâneas da contestação social de jovens em Belo Horizonte. Dissertação de mestrado apresentada ao programa de pós-graduação em educação da UFMG. Belo Horizonte, 2012.

PRESS, A. K. Constituent Imagination: Militant Investigations//Collective Theorization. London: AK Press, 2007.

SANDOVAL, Chela. Methodology of the Oppressed. Minneapolis: University of Minnesota Press, 2000.

SCOTT, James. Formas cotidianas de resistência camponesa. Porto Alegre; Deriva, 2014. 
SILVA, Áurea Carolina de Freitas. Mulheres jovens e o problema da inclusão: novidades no II Plano Nacional de Políticas para as Mulheres. In: PAPA, Fernanda de Carvalho e SOUSA, Raquel. Jovens Feministas Presentes. São Paulo: Ação Educativa/Fundação Friedrich Ebert, 2009.

SOUSA, Janice Tirelli Ponte. A experiência contemporânea da política entre jovens do sul do Brasil. Relatório de Pesquisa. Buenos Aires: CLACSO, 2014.

. Os jovens anticapitalistas e a ressignificação das lutas coletivas. Revista Perspectiva. Florianópolis, v.22, n.02, p.451-470, jul./dez. 2004.

\title{
Intergenerational conflicts and bridges in autonomist feminist translocal Latin American resistances
}

\begin{abstract}
The practices and proposes of youth feminisms are diverse and have gained more expression in the feminist field. Through fieldwork and interviews with participants, the research mapped youth feminist practices, focusing autonomist feminist gatherings and festivals that happened in Brazil, including a LatinAmerican, from 2011 to 2014. Situating these expressions in its continuities and ruptures with other feminist activisms through the movement's historical trajectory, and reviewing the debates and conflicts that have taken place in Latin American gatherings in the last decades political context, we analyzed how the autonomist feminist youth seek social transformation through the formation of resistance communities and cultures which offer the support to enable the living relations shaped by feminist principles in the present and in quotidian bases. These activisms are characterized by the creation of methodologies and pedagogies for the construction of self consciousness and self determination through the sharing of subjective experiences, interpretative framings for the reality, techniques of self defense and other bodily micropolitics. The analyses of the field concentrated in organizational practices of the movements, presenting and reflecting critically based on the discourses of the research collaborators on proposes on autonomy, self-management and do-it yourself, the creation of spaces for women, lesbians and trans, the creation of mutual care and support, and the search for horizontality. The research also analyzed conflicts over power relations and the forms of fighting oppression within feminists, specially ageism and adultcentrism, lesbophobia, transphobia, racism and speciesism.
\end{abstract}

Key-Words: Feminisms. Youth. Autonomy. Social movements. Latin America. 